\title{
Spatial Distribution of Toxocariaisis in Dogs
}

\author{
Shahida Azhar Ali ${ }^{1},{ }^{*}$ Tanveer Akhtar ${ }^{2}$, Wajid Safi ${ }^{3}$ \\ ${ }^{1}{ }^{2}$ Department of Zoology, University of the Punjab, Quaid-e-Azam Campus, Lahore, Pakistan \\ ${ }^{3}$ Solid Waste Management Corporation, Lahore.
}

\section{Part of Ph.D. thesis of first author}

\begin{abstract}
Toxocariasis is a zoonosis caused by larval stage of Toxocara canis (T.canis) an intestinal roundworm of dog; definitive host shed 1.4 million eggs / day in environment. In the present study the overall prevalence (\%) of T.canis in pet pups in slums of Lahore was $30.39 \%$. The highest prevalence $34.3 \%$ was observed in faecal samples of pet pups of Sheikhpura Road followed by $32.33 \%$ in Siddiquia Colony, $30.67 \%$ in Scheme No 2, $28.67 \%$ in Bhutto Colony and the lowest $26.7 \%$ in Khairdin Park. The prevalence was found to be $15.3 \%, 17.3 \%, 13.0 \%, 18.3 \%, 25.3 \%$ and $16.0 \%$ in six urban areas including Allama Iqbal Town, Wapda Town, ValenciaTown, Cantt, Gulberg and Samanabad respectively. The occurrence of the parasites was similar $(p<0.05)$ in all six urban localities. A significant prevalence $44 \%$ was observed in July. The pups were more parasitized $(p<0.001)$ with Toxocara compared to adult dogs. Similarly, the prevalence was more $(p<0.05)$ in female dogs compared to male dogs. Female (48.9\%) were more infected as compared to males (18.7\%) respectively. One way ANOVA ( Z-test) was applied to calculate the prevalence. Morphological identification of eggs was based on direct smear technique and Flotation Method.

Key words: Prevalence, Toxocariasis, Environment, Contaminated soil, Deworming
\end{abstract}

Objective: To provide awareness to pet owners to deworm their pups, minimize soil contamination that is a risk for human.

\section{Introduction And Literature Review}

Toxocariasis is a zoonosis causes by larval stage of Toxocara canis (T.canis) (Barrera et al., 2010). It is an intestinal roundworm of dog (Despommier et al., 2003) that is the definitive host (Sariego et al., 2012) especially pups of age less than 6 month old (Edosomwan et al., 2012). Infected pups who are risk factor shed eggs via faces in environment (Wisniewska-Ligier et al., 2012) i.e. contaminate soil of playground / parks (Bojarand Klapec, 2012), vegetables, raw fruits (Borecka et al., 2010).

\section{Importance Of Toxocara Canis In Pups}

A few week old infection in infective puppies causes digestive disorder, dirrahoea, vomiting, flatulence and loss of vitality (Glickman and Schantz, 1981). Adult T. canis cannot enter the human body Niedworok et al., 2008), only the infective larval stage as it causes an allergic disorder in man.

Coprological examination of 26 faecal samples of dogs showed prevalence $2(7.7 \%)$ of T.canis in Turkey. The highest prevalence 7 eggs / $\mathrm{g}$ of soil were found in parks situated near the slaughter house where stray dogs wandered (Ozkayhan,2006). Analysis of 50 faecal analysis, adults dogs showed $40.7 \%$ prevalence, $82.6 \%$ in young and overall prevalence was $60 \%$ in Iran, whereas male and female were equally infected (Daryani et al., 2009). In Poland highest prevalence (2.67 \% to $55 \%$ ) was observed in both domesticated and stray dogs of rural and urban areas (Kandala et al., 2011). Coprological analysis of 295 faecal samples of dogs showed overall prevalence $33.6 \%$ in Italy, out of it $48.4 \%$ dogs belong to rural communities and $26.2 \%$ of urban areas. Hunting dogs of rural had highest infection $64.7 \%$ followed by urban $22.1 \%$, whereas $40 \%$ dogs defecated in pens were infected, $24 \%$ belonged to urban and $47 \%$ from rural areas those who dropped their faeces in surroundings of houses (Habluetzel et al.,2003). In Palestine out of 132 faecal samples of dogs, overall prevalence $36.4 \%$ was observed, out of them $52.3 \%$ were of the age 6 months, $34.3 \%$ ranged from 6-12 months and $25 \%$ more than 12 months old respectively (Othman, 2011). A total of 396 dogs were examined for VLM, $45.5 \%$ were male and $54.5 \%$ female, and $48 \%$ belonged to urban areas and $52 \%$ of rural areas (Ugbomoiko et al., 2008).

\section{Material And Methods}

The study was carried out on pet dogs that were brought to the pet center, University of Veterinary and Animal Health Sciences, Lahore and other private clinics located in six slums ad six urban areas of Lahore i.e. Bhutto Colony, Siddiquia Colony, Scheme No. 2, Sheikhpura Road, Khairdin Park and Missri Shah and urban 
including Allama Iqbal Town, Wapda Town, Valencia Town, Lahore Cantonment (Cantt), Gulberg and Samanabad respectively from November 2008 to October 2009.

\section{Prevalence Of Toxocara Canis}

A total of 3600 faecal samples of pet dogs $25 /$ month / locality/ year were collected.

\section{Coprological Examination}

About $3 \mathrm{~g}$ of faecal samples of 1800 pet dogs were randomly collected directly from the rectum of each dog, immediately transferred to Department of Parasitology, University of Veterinary and Animal Health Sciences, Lahore. These were processed on the same day, if not then preserved in $10 \%$ formalin solution to prevent emberoynation / hatching. Following techniques were used to examine the faecal samples.

\section{Direct Smear Technique}

A small drop of water was mixed with equal volume of faecal material on glass slide, mixed thoroughly, covered with cover slip and examined under microscope (10x) (Hendrix and Robinson, 2006).

\section{Flotation Technique}

About $1 \mathrm{~g}$ of faecal sample was added to $10 \mathrm{ml}$ of $4 \% \mathrm{NaCl}$ solution and mixed thoroughly. A cover slip was placed into a test tube. Additional $4 \% \mathrm{NaCl}$ was added to overflow; cover slip was placed on the upper surface of the test tube and left standing for 10 to 15 minutes. The cover slip was removed vertically and examined under microscope (10x) (Zajac and Conboy, 2006).

\section{Application Of Geographical Information System (GIS)}

The Geographical Information System (GIS), a digital data base management system (Guiqin et al., 2009) was applied to facilitate quick understanding, elaborated the research work, showed links between transmission and spatial distribution (Gorsevski et al., 2012). Window 2007 and Arc GIS 9.3 were used. Spatial data about slums of northern Lahore marked for research work was collected physically from the Solid Waste Management (SWM) and Geographical Information Department of Punjab Government (IRIS). In order to create true visual impact of variations in the measurements, the type of classification that had been used is Natural Breaks (junk). In this classification the classes are formulated on the basis of natural groupings inherent in the data. The used software picked up break points of classes that best group similar values and therefore enhance the variations in the data.

\section{Application Of Thematic Disease Maps}

Spatial information, diagrammatical representation, geographical distribution and position of slums of northern Lahore and spatial distribution of observed Toxocara canis's eggs in contaminated soil samples was organized by tabulating all data in Excel 2007 and then export to Arc GIS 9.3 to draw thematic disease maps to show several layers in a sequence.

\section{Statistical Analysis}

All the data was entered in Excel 2007 for $Z$ test analysis and in SPSS version 15.0. The prevalence values were calculated by dividing the positive samples by total number of samples.

Results: Epidemiology of Toxocara canis in dogs of Lahore, Punjab, Pakistan: This part of the study was launched for one-year from November 2008 to October 2009 in urban and slums of Northern Lahore City.

\section{Prevalence of Toxocara canis in pups and adult dogs in slums:}

The prevalence of T.canis was $28.67 \%, 32.33 \%, 30.67 \%, 34.33 \%, 26.33 \%$ and $30 \%$ in Siddiquia Colony, Scheme No. 2, Bhutto Colony, Sheikhupura Road, Khairdin Park and Missri Shah respectively, an overall prevalence was found to be $30.3 \%$ in slums (Table 1) out of 1800 faecal samples of pups. Prevalence $(\%)$ was more frequently $(\mathrm{p}<0.001)$ found in July $44 \%$ compared to January $19.33 \%$ (Table $1,2)$. The pups were more $(\mathrm{p}<0.001)$ parasitized with toxocariasis as compared to adults (Table 1,2). Seasonwise highest prevalence (17.92\%) was observed in summer followed by $(17.17 \%)$ in autumn, $(13.50 \%)$ in spring and $(12.33 \%)$ in winter (Table 1,2).

\section{Prevalence of Toxocara canis in pups and adult dogs in urban areas}

A total of 1,800 faecal samples of pet dog from six urban areas were examined, 317 samples $(17.61 \%)$ were found positive for toxocariaisis. The prevalence was found to be $18.76 \%, 19 \%, 14 \%, 11$ $\%, 25.7 \%$ and $17.33 \%$ in Allama Iqbal Town, Wapda Town, Valencia Town, Lahore Cantonment (Cantt), Gulberg and Samanabad respectively. The occurrence of the parasites was similar $(\mathrm{p}<0.05)$ 
in all six urban areas (Table 1). The prevalence of the parasites was more $28 \%(\mathrm{p}<0.01)$ in July compared to $12.67 \%$ lowest in January and September (Table 1,2). Seasonwise high prevalence was observed $(9.83 \%)$ in summer followed by $(8.67 \%)$ in winter, $(8.50 \%)$ in spring and $(7.33 \%)$ in autumn (Table 1,2$)$. The pups were more parasitized $(\mathrm{p}<0.001)$ as compared to adult dogs. Similarly the prevalence was more $(\mathrm{p}<0.05)$ in female dogs compared to male dogs (Table 1,2$)$.

\section{Overall Prevalence Of Toxocara canis In Pups And Adult Dogs Faecal Samples}

Out of 3,600 examined faecal samples, 864 (24\%) naturally infected dogs and pups were positive for toxocariaisis in both studied areas (Table 1,2). The parasites were more frequently $(\mathrm{p}<0.001)$ found in pups as compared to adult dogs (Table 1,2). The female dogs were observed $(\mathrm{p}<0.01)$ more frequently parasitized than male dogs (Tables 1,2). The prevalence in naturally infected pups was more $(\mathrm{p}<0.001)$ in slums 30.39 $\%$ as compared to urban areas $17.61 \%$ (Tables 1,2). "Thematic disease map 1" showed prevalence of toxocariasis in pups of slums and urban areas of Lahore.

\section{Discussion}

Dogs represented themselves as an important host causing environmental contamination with $T$. canis eggs. In the present study $23.9 \%$ faecal samples were found positive for $T$. canis. Considerable variations have been found regarding the prevalence in different regions of the world. The results of the present study were comparable with the others (Barutzki and Schaper, 2003; Bridger and Whitney, 2009). A few reports also demonstrated quite higher prevalence rates compared to the present study (Minnaar and Krecek, 2001; Habluetzel et al, 2003).

Results of the present study showed that overall prevalence of canine Toxocara was lower $(\mathrm{p}<0.05)$ in urban (17.6\%) compared to slums $(30.3 \%)$. The prevalence was quite similar $(p>0.05)$ in various localities of the urban area $(13.0 \%$ to $25.3 \%)$. Similarly no statistical difference $(\mathrm{p}<0.05)$ was noted when the prevalence rate was compared among various slums (26.0\% to $32.0 \%)$. Epidemiological investigation in the present study showed that infection rate varies with geographic area and had been found to be higher in slums than in urban areas. This demographic factor seemed to be very important in the transmission of canine Toxocara in dogs and humans. The high prevalence rate in slums posed high risk of transmission of the parasites in other animals and humans. It had been found that the prevalence of canine T. canis was more in the rural than in the urban zone (Fok et al., 2001). The results of the current study are in agreement with the findings of (Habluetzel et al., 2003) who noted twice as many dogs from rural areas $(48.4 \%)$ harboured T. canis compared to the urban $(26.2 \%)$ ones in Italy. This difference might be due to frequent anthelmintic treatments of urban dogs due to a greater health consciousness of their owners who usually kept dogs for company so that they often had close contact with the family members. Another factor for this difference between urban and rural dogs might be results of the persistent custom of rural people feeding their dogs with un-cooked food. In contrast people living in the urban areas of Lahore were accustomed to feed their dogs either commercially-available pet food or at least feed them partially cooked home-made food. An association between the frequency of veterinary assistance and presence of gastrointestinal parasites in dogs had been documented by (Martini et al., 1992) who worked on dogs from a semiurban area of Bologna Province. It might also be that rural dogs more frequently acquire $T$. canis infections through the ingestion of paratenic hosts such as Mits spp and Apodemus spp.

In the present study the influence of sex on the occurrence of toxocariasis was evident in both localities. In urban areas the parasites were more $(\mathrm{p}<0.05)$ prevalent in females $(20.8 \%)$ as compared to males $(15.7 \%)$. Same trend was noted in slums where the parasites were more $(\mathrm{p}<0.01)$ common in females dogs $(48.9 \%)$ compared to male dogs (18.6\%). Results from a previous study conducted in French Island of St. Pierre (Bridger and Whitney, 2009) supported the findings of the current study where T. canis was more abundant in female (27.3\%) dogs compared to males (11.8\%). However (Rubel et al., 2003) observed that T. canis was more abundant in males compared to females in a study conducted in the Buenos Ares, Argentina. The apparent lack of any difference in distribution in the urban area might be due to the number of samples examined. In the current epidemiological investigation, the number of male dogs examined for canine Toxocara was twice the number of females. Therefore this unequal assortment of gender-based sample size might also be considered while comparing the results of present study with the others. Therefore researchers should be very careful while interpreting the results as the number of samples examined should also be taken into the account.

With regard to the relationship between T. canis infection and host age, some experimental studies had suggested that the probability of $T$, canis to successfully complete its life cycle decreases gradually during the first year after host birth, due to age-related resistance (Greve, 1971). An inverse relationship between the prevalence rate of canine T.canis and age of host was found in the current study indicating ageassociated resistance. Coporological results from the present study based on age showed that pups were more frequently infected with canine T. canis as compared to adults in both localities. Recently (Roddie et al., 2008) and (Aydenizoz-Ozkayhan et al., 2008) also found that the higher numbers of T. canis eggs in pup's hairs, as 
compared to adults, associated with a higher risk factor for disease transmission. In experimental infections, the highest worm loads occurred in of pups less than one-month old (Lloyd, 1993). (Rubel et al., 2003) demonstrated that the prevalence rate decreased linearly with age, being more in pups (53\%) of less than one year-old compared to dogs > two years old (13\%). (Habluetzel et al., 2003) also found that prevalence of T.canis infection declined with age. The higher prevalence rate in young dogs compared to adult could be due to the mode of transmission of the parasites. Pups could be infected transplacently and transmammary in their first few days of life that increased the occurrence of the parasites at an early age, whereas adult dogs might develop immunity which decreases the establishment as well as the fecundity of the parasite (Urquhart et al., 1996). Although the occurrence of the parasites was greater in puppies compared to adults, still the prevalence was considerably higher in adult dogs showing that adult dogs could acquire the infection under natural or experimental conditions and shed eggs to the environment, despite the occurrence of humoral response (Oliveira-Sequeria et al., 2002). Another possible explanation for occurrence of the parasites in adult dogs could be exposure of the infections at a later stage instead of early age and, therefore, lack of elicitation of immune response. Moreover the development of infection in older dogs might be more than coincidence due to particular circumstances like consumption of infected paratenic hosts, immuno suppress ion or even hormonal changes.

In respect to the factors affecting the prevalence of infection, it is clear that meteorological factors including temperature, humidity and rainfall had substantial effects on the prevalence of toxocariasis. Results of the present study demonstrated that summer provided optimum conditions in terms of temperature and humidity for speeding the life cycle. In the present study, the parasites were more frequently found in summer during the months of June to July in all the areas studied, T.canis had been found to have a high dependence on humidity and high temperatures where the prevalence was higher in hot summer compared to winter (Ponce-Macotela et al., 2005). The higher prevalence in summer season was obvious as T.canis eggs hatch in the soil at warm temperatures and high humidity.

\section{Conclusion}

For the first time in Pakistan GIS was applied for designing thematic disease maps to show spatial distribution of helminthes in human residents of slums and urban areas of northern Lahore. Pups were more infected as compared to adult dogs. The government should have to achieve the goals of reduction or elimination of helminth infections by developing novel tools including deworming, drug efficacy, new diagnostic techniques and use of advanced software of GIS to update thematic disease maps.

\section{References}

[1] Aydenizoz-Ozkayhan, M., Yagci, B.B., and Erat, S., 2008. The investigation of Toxocara canis eggs in coats of different dogs breeds as a potential transmission route in human toxocariasis. Vet. Parasitol., 152: 94-100.

[2] Barutzki, D.and Schaper, R., 2003. Endoparasites in dogs and cats in Germany 1999-2002. Parasitol. Res.,90:S148-s150.

[3] Bridger, K.E. and Whitney, H., 2009. Gastrointestinal parasites in dogs from the Island of St. Pierre off the south coast of Newfound land. Vet. Parasitol.,162: 167-170.

[4] Fok, E., Szatmari, V., Busak, K. and Rozgonyi, F., 2001. Prevalence of intestinal parasites in dogs in some urban and rural areas of Hungary. Vet. Q., 23: 96-98.

[5] Gorsevski, P.V., Donevska, K.R., Mitrovski, C.D. and Frizado, J. P., 2012. Integrating multi-criteria evaluation techniques with geographic information systems for landfill site selection: A case study using ordered weighted average. Waste Management, 32: $287-296$.

[6] Greve, J. H., 1971. Age resistance in to Toxocara canis in ascarid free dogs. Am. J. Vet. Res.,32: 1185-1192.

[7] Guiqin, W., Guoxue, Q.L.L. and Lijun, C., 2009. Landfill site selection using spatial information technologies and AHP: A case study in Beijing, China. J. Env. Man., 90: 2414-2421.

[8] Habluetzel, A., Traldi, G., Ruggieri, S., Attili, A.R., Scuppa, P., Marchetti, R., Menghini, G. and Esposito, F., 2003.An estimation of Toxocara canis prevalence in dogs, environmental egg contamination and risk of human infection in the Marche region of Italy. J. Vet. Parasitol.,113: 243-252.

[9] Hendrix, C. N., and Robinson, E., 2006. Diagnostic Parasitology for Veterinary Technicians. $6^{\text {th }}$ Ed., Mosby Inc, Elsevier, USA. 252253.

[10] Lloyd, S., 1993. Toxocara canis: the dog. Toxocara and Toxocariasis Clinical Epidemiologycal and Molecular Perspectives London. J.W Lewis R.M.Maizels Ed. Institute of Biology. Pp.11-19.

[11] Martini, M., Poglayen, G., Minerva, N. and Zanangeli, A., 1992.A study of factors influencing intestinal parasites in dogs.Ann. 1st Super Sanita.,28: $477-484$

[12] Minnaar, W.N., Krecek, R.C. and Fourie, L.J. 2002. Helminths in dogs from a periurban resource-limited community in Free State Province, South Africa. Vet. Parasitol.,107: 343-349.

[13] Oliveira-Sequeira, T.C., Amarante, A.F., Ferrari, T.B. and Nunes, L.C., 2002. Prevalence of intestinal parasites in dogs from Sao Paulo State, Brazil.Vet. Parasitol.,3: 19-27.

[14] Ponce-Macotela,M.,Peralta-Abarca,G.E. and Martinez-Gordillo, M.N., 2005. Giardia intestinalis and other zoonotic parasites: prevalence in adult dogs from the southern part of Mexico City. Vet.Parasitol.,131:1-4.

[15] Roddie, G., Stafford, P., Holland, C. and Wolfe, A., 2008. Contamination of dog hair with eggs of Toxocara canis. Vet. Parasitol.,25: 85-93.

[16] Rubel, D., Zunino, G., Santillán, G. and Wisnivesky, C., 2003. Epidemiology of Toxocara canis in the dog population from two areas of different socioeconomic status, Greater Buenos Aires, Argentina. Vet. Parasitol.,115:275-286.

[17] Urquhart, G. M., Amour, J. L., Duncan, A. M. and Jennings, F. W., 1996. Veterinary Parasitology.3rd Ed. ELBS Longman, UK.213-218. 
[18] Zajac, A. M., and Conboy, G., 2006. In: Veterinary Clinical Parasitology. Blackwell Publishing, Iowa, pp: 283. 
Table 1: Overall areawise, monthwise and, seasonwise prevalence $(\%)$ of (Toxocara canis) in faecal samples of pups of slums of Lahore, Punjab, Pakistan from November 2008- October 2009

\begin{tabular}{|c|c|c|c|c|c|c|c|c|}
\hline \multirow{2}{*}{ 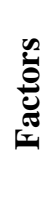 } & \multicolumn{3}{|c|}{ Total $n=1800$} & \multirow{2}{*}{$\begin{array}{l}\text { Prevalence } \\
(\% \pm \text { S.E })\end{array}$} & \multicolumn{3}{|c|}{ Total $n=1800$} & \multirow{2}{*}{$\begin{array}{l}\text { Prevalence } \\
(\% \pm \text { S.E })\end{array}$} \\
\hline & Slums & $\begin{array}{l}\text { Obs } \\
\text { erve } \\
\text { d }\end{array}$ & $\begin{array}{l}\text { Infect } \\
\text { ed }\end{array}$ & & Urban areas & $\begin{array}{l}\text { Obs } \\
\text { erve } \\
\text { d }\end{array}$ & $\begin{array}{l}\text { Infe } \\
\text { cted }\end{array}$ & \\
\hline \multirow{6}{*}{ 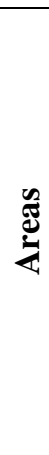 } & $\begin{array}{l}\text { Bhutto } \\
\text { Colony }\end{array}$ & \multirow{6}{*}{ 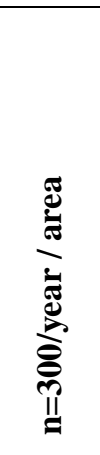 } & 86 & $28.67 \pm 2.61$ & $\begin{array}{l}\text { Allama Iqbal } \\
\text { Town }\end{array}$ & \multirow{6}{*}{ 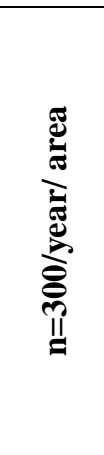 } & 56 & $18.67 \pm 2.25$ \\
\hline & $\begin{array}{l}\text { Siddiquia } \\
\text { Colony }\end{array}$ & & 97 & $32.33 \pm 2.70$ & Wapda Town & & 57 & $19.00 \pm 2.26^{* * *}$ \\
\hline & $\begin{array}{l}\text { Scheme No. } \\
2\end{array}$ & & 92 & $30.67 \pm 2.66$ & $\begin{array}{l}\text { Valencia } \\
\text { Town }\end{array}$ & & 42 & $14.00 \pm 2.00 * * *$ \\
\hline & $\begin{array}{l}\text { Sheikhupura } \\
\text { Road }\end{array}$ & & 103 & $34.33 \pm 2.74$ & Cantt & & 33 & $11.00 \pm 1.81^{* * *}$ \\
\hline & $\begin{array}{l}\text { Khairdin } \\
\text { Park }\end{array}$ & & 79 & $26.33 \pm 2.54$ & Gulberg & & 77 & $25.67 \pm 2.52 * * *$ \\
\hline & Missri Shah & & 90 & $30.00 \pm 2.65$ & Samanabad & & 52 & $17.33 \pm 2.19 * * *$ \\
\hline \multirow{13}{*}{ 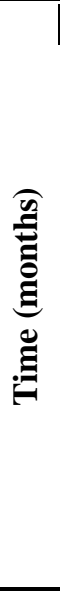 } & Total & 1800 & 547 & $30.39 \pm 1.08$ & Total & 1800 & 317 & $17.61 \pm 0.90 * * *$ \\
\hline & Nov 2008 & \multirow{12}{*}{ 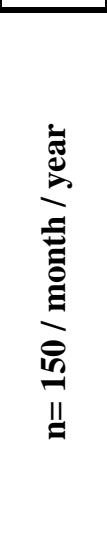 } & 43 & $28.67 \pm 3.69$ & Nov 2008 & \multirow{12}{*}{ 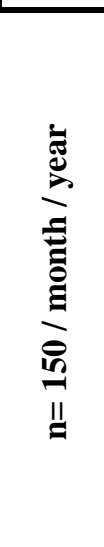 } & 24 & $16.00 \pm 2.99$ \\
\hline & Dec 2008 & & 30 & $20.00 \pm 3.27$ & Dec 2008 & & 28 & $18.67 \pm 3.18$ \\
\hline & Jan 2009 & & 29 & $19.33 \pm 3.22$ & Jan 2009 & & 19 & $12.67 \pm 2.72$ \\
\hline & Feb 2009 & & 46 & $30.67 \pm 3.76$ & Feb 2009 & & 33 & $22.00 \pm 3.38$ \\
\hline & Mar 2009 & & 33 & $22.00 \pm 3.38$ & Mar 2009 & & 22 & $14.67 \pm 2.89$ \\
\hline & Apr 2009 & & 48 & $32.00 \pm 3.81$ & Apr 2009 & & 29 & $19.33 \pm 3.22$ \\
\hline & May 2009 & & 59 & $39.33 \pm 3.99$ & May 2009 & & 29 & $19.33 \pm 3.22$ \\
\hline & Jun 2009 & & 43 & $28.67 \pm 3.69$ & Jun 2009 & & 24 & $16.00 \pm 2.99$ \\
\hline & Jul 2009 & & 66 & $\begin{array}{l}44.00 \pm 4.05^{*} \\
*\end{array}$ & Jul 2009 & & 42 & $28.00 \pm 3.67 * *$ \\
\hline & \multirow{2}{*}{\begin{tabular}{|l|} 
Aug 2009 \\
Sep 2009 \\
\end{tabular}} & & 47 & $31.33 \pm 3.79$ & Aug 2009 & & 23 & $15.33 \pm 2.94$ \\
\hline & & & 48 & $32.00 \pm 3.81$ & Sep 2009 & & 19 & $12.67 \pm 2.72$ \\
\hline & Oct 2009 & & 55 & $36.67 \pm 3.93$ & Oct 2009 & & 25 & $16.67 \pm 3.04$ \\
\hline \multicolumn{2}{|r|}{ Total } & 1800 & 547 & $30.39 \pm 1.08$ & Total & 1800 & 317 & $17.61 \pm 0.90^{* * *}$ \\
\hline \multirow{4}{*}{ 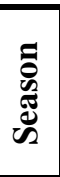 } & Winter & 600 & 148 & $12.33 \pm 0.95$ & Winter & 600 & 104 & $8.67 \pm 1.55$ \\
\hline & Spring & 300 & 81 & $13.50 \pm 1.40$ & Spring & 300 & 51 & $8.50 \pm 1.14$ \\
\hline & Summer & 600 & 215 & $17.92 \pm 1.11$ & Summer & 600 & 118 & $9.83 \pm 0.86$ \\
\hline & Autumn & 300 & 103 & $17.17 \pm 1.54$ & Autumn & 300 & 44 & $7.33 \pm 1.06$ \\
\hline \multicolumn{5}{|c|}{ Overall prevelance (\%)(Slums+Urban) } & \multicolumn{2}{|c|}{$\begin{array}{l}\mathrm{n}=1800 * 2=3600 / \\
\text { year }\end{array}$} & 864 & $24.00 \pm 0.17 * * *$ \\
\hline
\end{tabular}

$* \mathbf{P}<.05, * * \mathbf{P}<.01, * * * \mathbf{P}<.001$ Z-test 
Spatial Distribution Of Toxocariaisis In Dogs

Table 2: Overall monthwise prevalence (\%) of pups and adults dogs infected with Toxocara canis in slums and urban areas of Lahore, Punjab, Pakistan from Nov 2008 to Oct 2009

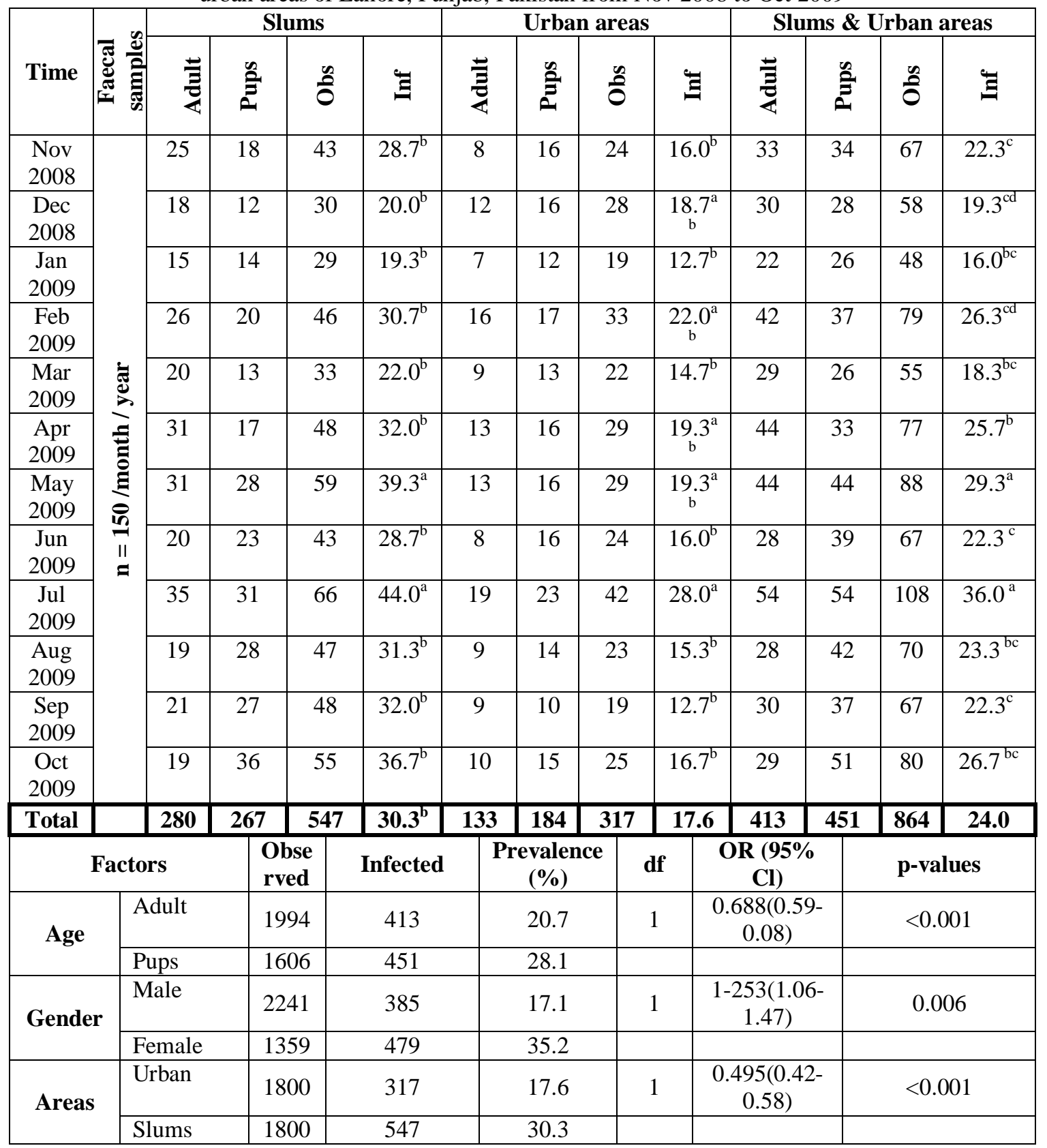

Values with no common superscripts in a same column differ significantly $(\mathrm{p}<0.05)$

Abbreviation:- ob (observed). Inf (infected), $\mathrm{OR}=\mathrm{Odd}$ ratio, $\mathrm{Cl}=\mathrm{Confidence}$ interval 


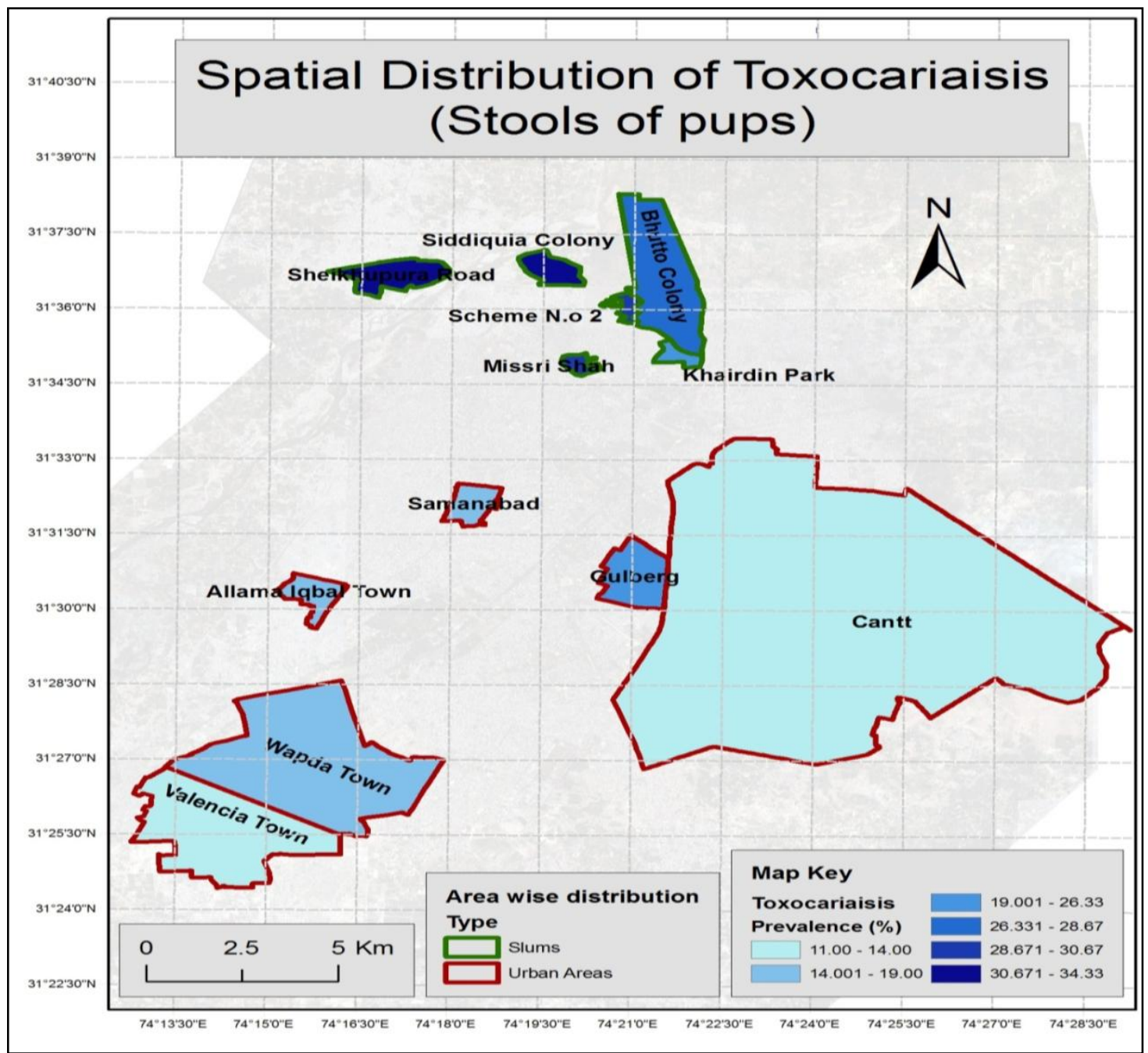

Fig. 1: Thematic disease map 1: Spatial distribution of toxocariaisis (stools of pups) in northernLahore from Nov.2008 to Oct. 2009. 